\title{
JOGOS AFRICANOS E AFRO- BRASILEIROS: uma proposta sociocultural para o ensino
}

\section{JOÃO DE DEUS FONSECA JUNIOR}

Mestre em História da África das Diásporas e dos Povos Indígenas pelo Centro de Artes, Humanidades e Letras da Universidade Federal do Recôncavo da Bahia (UFRB). Linha de Pesquisa: Educação Interétnica. Grupo de Pesquisa, FORCCULT. ORCID: 0000-0003-3364-0410. E-mail: joaodedeus22@hotmail.com

\author{
RITA DE CÁSSIA DIAS PEREIRA ALVES \\ Universidade Federal do Recôncavo (UFRB). Doutora em Educação (UFBA). Professora \\ Associado I da Universidade Federal do Recôncavo (UFRB). Centro de Cultura, Linguagens \\ e Tecnologias Aplicadas (CECULT), Santo Amaro - BA. Grupo de Pesquisa, FORCCULT. \\ ORCID: 0000-0002-2223-0945. E-mail: rcdias@ufrb.edu.br
}




\section{JOGOS AFRICANOS E AFRO-BRASILEIROS: uma proposta sociocultural para o ensino}

O Relato é fruto da pesquisa de mestrado realizada na Universidade Federal do Recôncavo da Bahia (UFRB), no Centro de Humanidades, Artes e Letras (CAHL) no município de Cachoeira-BA. O estudo apresenta a diversidade sociocultural do Recôncavo da Bahia, e suas conexões com outras regiões brasileiras nas quais tem a presença maciça das populações negras e afrodescendentes, tendo como objetivo, auxiliar na construção da teoria pedagógica dos jogos de origem africana e afro-brasileira, como uma proposta sociocultural, permitindo utilizá-los como recurso pedagógico para o ensino. O estudo propõe investigar a relevância das práticas de jogos e brincadeiras no processo educacional, de mostrar o valor educativo que poderá ser incorporado às atividades escolares. Concluímos que os jogos e as brincadeiras apresentam uma gama de possibilidades para prática educacional, estes, sendo utilizados com finalidades pedagógicas, podem gerar conhecimento das mais variadas áreas do conhecimento, tornando-se um importante recurso pedagógico para o ensino.

Palavras-chave: Educação. Sociocultural. Jogos.

\section{AFRICAN AND AFRO-BRAZILIAN GAMES: a sociocultural proposal for teaching}

The Report is the result of the Master's research carried out at the Federal University of Recôncavo da Bahia (UFRB), at the Center for Humanities, Arts and Letters (CAHL) in the city of Cachoeira-BA. The study presents the sociocultural diversity of the Recôncavo da Bahia, and its connections with other Brazilian regions in which there is a massive presence of the black and Afro - descendant populations. With the objective of assisting in the construction of the pedagogical theory of games of African and Afro-Brazilian origin, as a sociocultural proposal, allowing them to be used as a pedagogical resource for teaching. The study proposes to investigate the relevance of the practices of games and games in the educational process, to show the educational value that can be incorporated into school activities. We conclude that games and games present a range of possibilities for educational practice, which, being used for pedagogical purposes, can generate knowledge from a wide variety of areas of knowledge, making it an important pedagogical resource for teaching.

Keywords: Education. Cultural Partner. Games.

\section{JUEGOS AFRICANOS Y AFRO-BRASILEÑOS: una propuesta sociocultural para la enseñanza}

La historia es fruta del llevada con la investigación del mestrado en la universidad federal del Recôncavo de la Bahía (UFRB), en el centro de la humanidad, de los artes y de Letras (CAHL) en la ciudad de la cascada. El estudio presenta la diversidad sociocultural del Recôncavo de la Bahía, y sus conexiones con otras regiones brasileñas en las cuales tenga la presencia masiva de las poblaciones del negro y de los afrodescendentes, teniendo como objetivo, asistir a la construcción de la teoría pedagógica de los juegos del origen africano y afro-Brasileño, como oferta sociocultural, permitiendo para utilizarlos como recurso pedagógico para la educación. El estudio que considera para investigar la importancia de práctico de juegos y de los trucos en el proceso educativo, para demostrar el valor educativo que podría ser incorporados referente a actividades de la escuela. Concluimos que los juegos y los trucos presentan una gamma de las posibilidades de educativo práctico, éstos, siendo utilizado con propósitos pedagógicos, podemos generar el conocimiento de las áreas más variadas del conocimiento, haciendo un recurso pedagógico importante para la educación.

Palabras clave: Educación. Sociocultural. Juegos.

\section{plupais}

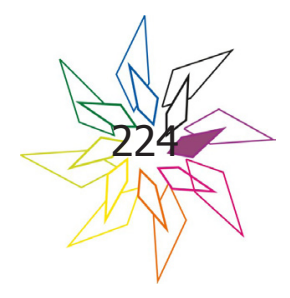




\section{JOGOS AFRICANOS E AFRO-BRASILEIROS: uma proposta sociocultural para o ensino}

\section{Introdução}

O estudo apresenta a diversidade sociocultural do Recôncavo da Bahia, e suas conexões com outras regiões brasileiras nas quais tem a presença maciça das populações negras e afrodescendentes. Este artigo é fruto da pesquisa de mestrado realizada na Universidade Federal do Recôncavo da Bahia (UFRB), no Centro de Humanidades, Artes e Letras (CAHL) no município de Cachoeira-BA. O estudo tem como objetivo, auxiliar na construção da teoria pedagógica dos jogos de origem africana e afro-brasileira, como uma proposta sociocultural, permitindo utilizá-los como recurso pedagógico para o ensino na escola básica, especificamente no Ensino Fundamental dos Anos Iniciais.

Desta forma, torna-se necessário refletir em relação à dicotomia entre o jogar e o aprender instalada nos ambientes escolares. Atualmente, percebe-se que a utilização dos jogos como proposta pedagógica, na maioria das vezes, tem sido tratada de forma secundária. Observamos que esse tipo de atividade é utilizado como momentos de relaxamento, descanso e desgaste de energia excedente das crianças. Contudo, é sabido que o jogo e a brincadeira são recursos importantes da formação de crianças, porém, essa prática permanece dissociada do processo educativo.

Desta forma, o estudo propõe investigar a relevância das práticas de jogos no processo educacional, e de mostrar o valor educativo que poderá ser incorporado às atividades escolares. Assim, apresentamos um estudo a partir da pesquisa desenvolvida na área dos jogos de origem africana e afro-brasileira, pois, o que presenciamos atualmente nos ambientes educacionais da rede pública de ensino, fica restrito à prática de capoeira e maculelê, e geralmente em datas comemorativas, além disso, muitas vezes essas intervenções são realizadas por pessoas da comunidade.

Para aplicar os jogos de origem africana e afro-brasileira, apresentamos a proposta metodológica, por meio das Rodas de Saberes e Formação (RSF), no início e no final de cada atividade. Por entender que as rodas horizontalizadas propiciam condições para que os participantes possam assumir-se como seres históricos, culturais e pensantes. Momento este, utilizado para: apresentação, contextualização e avaliação dos jogos, bem como, abordagem dos conteúdos discutidos em cada jogo.

\section{plurais}




\section{Metodologia}

A proposta metodológica apresentada aborda uma pesquisa qualitativa no campo epistemológico, estudo fenomenológico de abordagem multirreferencial, segundo Gil (2008, p. 14): “o pesquisador preocupa-se em mostrar e esclarecer o que é dado. Não procura explicar mediante leis, nem deduzir com base em princípios, mas considera imediatamente o que está presente na consciência dos sujeitos". Pensamos sob uma perspectiva epistemológica multirreferencial, por esta possibilitar a compreensão do fenômeno educativo a partir de uma pluralidade de olhares e de linguagens, reconhecidos como necessários à compreensão da complexidade inerente a esse processo.

Para Ardoino (1998), citado por Macedo (2012, p. 118), a abordagem multirreferencial exige,

[...] uma leitura plural desses processos tanto em sua natureza teórica enquanto prática; uma reflexão sob diferentes pontos de vista, o que implica tanto em visões específicas quanto linguagens apropriadas às descrições exigidas em função mesmo do uso de sistemas de referências distintos, considerados, reconhecidos explicitamente como não redutíveis uns aos outros, ou seja, heterogêneos.

Apresentamos também a proposta da educação intercultural, segundo Fleuri (1999, p.280), que indica uma situação em que pessoas de culturas diferentes interagem, ou uma atividade que requer tal interação. A ênfase na relação intencional entre sujeitos de diferentes culturas constitui o traço característico da relação intercultural. O que pressupõe opções e ações deliberadas, particularmente no campo da educação.

Apresentamos como proposta pedagógica a utilização de jogos de origem africana e afro-brasileira, que foram realizados por meio de aplicação dos jogos e das Rodas de Saberes e Formação (RSF), por entender que as rodas horizontalizadas propiciam condições para que os participantes possam assumir-se como seres históricos, culturais e pensantes.

Para Jesus e Nascimento (2016,p. 113), as Rodas de Saberes e Formação (RSF),

[...] nos levam a compreender as rodas como uma construção em curso, situada historicamente, contextualizada, um patrimônio cultural dos povos, e buscamos integrá-las à educação, tomando-as como inspiração para elaboração de um dispositivo pedagógico-curricular de formação em contextos culturais.

\section{plurais}

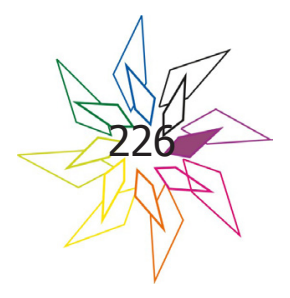


As (RSF) nos remetem à imagem circular, "como nas rodas de samba, de capoeira, de candomblé" (Jesus e Nascimento, 2016, p. 113) e de conversas, e horizontalizada, em que todos podem ensinar e contribuir com as experiências científicas, sociais, culturais em um contexto específico de formação dos sujeitos. Neste sentido, as (RSF) ocorreram antes e após a execução dos jogos, por meio de instrumentos didáticos, como, leitura de textos, exibições de vídeos, mostras de mapas, confecções de jogos e brinquedos e diálogos circulares.

\section{Os Jogos como Ação Cultural e Educativa}

Aqui, discutiremos os jogos como ação cultural e educativa, a intensão é, sobretudo, discutir o jogo como proposta sociocultural para o ensino. No decorrer deste texto, apresenta-se uma questão fundamental sobre o tema exposto: a problemática da diversidade cultural, relacionada aos jogos e suas implicações para o ensino. Desta forma, não podemos falar de diversidade cultural e não falar de cultura, entretanto, é admissível pensar que o conceito de cultura no singular pode ser considerado impróprio tendo em vista as culturas humanas em sua mais ampla variedade. Neste sentido, apresentamos o conceito de cultura segundo os pensamentos do Antropólogo Roque Laraia (2001, p. 31), afirmando que,

Culturas são sistemas (de padrões de comportamento socialmente transmitidos) que servem para adaptar as comunidades humanas aos seus embasamentos biológicos. Esse modo de vida das comunidades inclui tecnologias e modos de organização econômica, padrões de estabelecimento, de agrupamento social e organização política, crenças, práticas religiosas, e assim por diante.

Para o professor Kabengele Munanga (2015, p.10), a cultura deve ser entendida, não no seu sentido estreito que faz dela um sinônimo de apreciação das letras e belas artes, mas em seu sentido antropológico como conjunto dos conhecimentos, ideias, objetos que constituem a herança comum de uma sociedade. Herança, porque cada membro do grupo recebe através do processo educativo esse conjunto que foi constituído pelas gerações anteriores, fazendo-o seu. Herança comum porque todos os membros da sociedade participam dela. Neste sentido, vale ressaltar a reflexão historiador e antropólogo Anta Diop (2007, p. 308), que apresenta a cultura, especialmente cultura africana:

Eu considero a cultura um baluarte que protege um povo, uma coletividade. A cultura deve acima de tudo desempenhar uma função protetora; ela deve assegurar a coesão do grupo. Seguindo esta linha de pensamento a função vital do corpo de ciências humanas, é desenvolver este senso de bens coletivos

\section{plurais}


através de um reforço da cultura. Isso pode ser feito desenvolvendo-se o fator linguístico, restabelecendo-se a consciência do africano e do negro a ponto de fazê-los chegar a um sentimento comum de pertencimento ao mesmo passado histórico e cultural. Quando isto for feito, será muito mais difícil "dividir para reinar" e opor comunidades africanas umas contra as outras. Meu sentimento é o de que este seja o objetivo de um novo corpo de ciências humanas africanas, contanto que isso não se afaste do estrito termo científico. Isso é o mais importante: jamais se afastar da trilha da ciência.

Vimos conceitos e entendimentos sobre a cultura de forma geral, bem como a cultura africana. Agora buscaremos entender como é vista a cultura no campo da Educação Física. Assim, apresento os pensamentos do professor Jocimar Daolio (2004), para quem o termo "cultura" parece, definitivamente, fazer parte da educação física, fato impensável há duas décadas; e que sugere, no mínimo, que as ciências humanas têm influenciado a área.

Depois do predomínio das ciências biológicas nas explicações do corpo, da atividade física e do esporte por parte da educação física, essa tarefa, hoje, parece estar dividida com os conhecimentos provindos de outras áreas, tais como a antropologia social, a sociologia, a história, a ciência política e outras. (DAOLIO, 2004). Para o autor, muitos estudiosos da educação física, tentam compreender as manifestações corporais humanas considerando a perspectiva cultural. [...] Ainda que os principais autores da educação física no Brasil defendam propostas metodológicas diferentes, todos se referem à cultura, mais ou menos explicitamente. É possível perceber a utilização da expressão "cultura" acompanhada de termos como "física", "corporal", "de movimento" e outros. Daolio (2004, p. 09), refere-se à cultura e educação física como:

A "cultura" é o principal conceito para a educação física, porque todas as manifestações corporais humanas são geradas na dinâmica cultural, desde os primórdios da evolução até hoje, expressando-se diversificadamente e com significados próprios no contexto de grupos culturais específicos.

As concepções de cultura vistas à cima trazem contribuições importantes para a compreensão crítica dos fundamentos das relações interculturais na perspectiva educacional. Desta forma, caminharemos pelos caminhos da proposta interculturalista, que segundo Fleuri (2002b, p.407), a perspectiva intercultural da educação reconhece o caráter multidimensional e complexo da interação entre sujeitos de identidades culturais diferentes e busca desenvolver concepções e estratégias educativas que favoreçam o enfrentamento dos conflitos, na direção da superação das estruturas

\section{plurais}

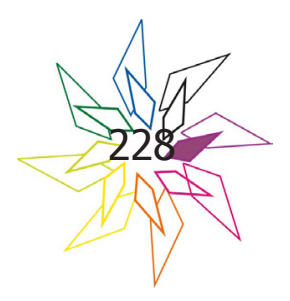


socioculturais geradoras de discriminação, de exclusão ou de sujeição entre grupos sociais. Para Fleuri $(1999$, p. 280), a educação intercultural requer que se trate nas instituições educativas os grupos populares não como cidadãos de segunda categoria, mas que se reconheça seu papel ativo na elaboração, escolha e atuação das estratégias educativas. Além disso, é preciso repensar as funções, os conteúdos, os métodos, o currículo da escola e acima de tudo o processo de formação dos professores de modo a se superar o seu caráter monocultural, buscando promover cada vez mais uma educação intercultural.

\section{O Jogo como Proposta Educativa}

Tendo o jogo como objeto do estudo, sendo esta uma temática da cultura corporal da criança, segundo o professor Marcos Neira (2016, p. 18), no ambiente escolar o/ professor/a deve investir numa proposta pedagógica intercultural, em que:

O professor/a deve empregar uma pedagogia em que um bom ensino é aquele que considera seriamente a vida dos/as estudantes abrindo espaços para a diversidade de etnias, classes sociais e gêneros das populações estudantis. O que se propõe é que os/as educadores/as investiguem e recuperem as experiências dos estudantes, analisando seus saberes sobre as práticas corporais e as formas com as quais suas identidades se inter-relacionam com essas manifestações.

Seguindo os pensamentos do autor acima citado, entendemos que ao propor um jogo, além de pensarmos no conteúdo que queremos ensinar, devemos sobretudo criar estratégias para apresentar o jogo a partir das experiências de vida dos estudantes, desta forma o jogo se tornará mais atraente e significativo.

Propondo os jogos como ação educativa, seguimos o pressuposto que a aprendizagem por meio do jogo que acontece em um contexto sociocultural, assim, se busca referência na teoria vygotskyana do desenvolvimento humano para apreender o sentido que ali é empreendido este conceito. Para Vygotsky (2010), o período escolar do desenvolvimento de uma criança tornam-se evidentes vários tipos de discrepância entre sua atividade — que já é bastante complexa neste estágio do desenvolvimento — e o processo de satisfação de suas necessidades vitais. [...] Esta atividade é, portanto caracterizada por uma ampla gama de ações que satisfazem necessidades que não se relacionam com seu resultado objetivo.

Em outras palavras, muitos tipos de atividades nesse período do desenvolvimento possuem seus motivos (aquilo que estimula a atividade) em si mesmos, por assim dizer. Quando, por exemplo, uma criança constrói com blocos, é claro que ela não age assim porque essa atividade leva a um certo

\section{plurais}


resultado que satisfaz a alguma de suas necessidades; o que a motiva a agir nesse caso aparentemente é o conteúdo do processo real da atividade dada. (VYGOTSKY, 2010, p. 119).

Abordando o jogo, o brinquedo e a brincadeira, para Vygotsky (1991b, p.61-62), defini-los como atividade prazerosa para criança, é incorreto por duas razões. Primeiramente, muitas atividades dão à criança experiências de prazer muito mais intensas do que o brinquedo, como por exemplo, chupar chupeta, mesmo que a criança não se sacie. E, segundo, existem jogos nos quais a própria atividade não é agradável. Seguindo o pensamento do referido autor, podemos observar uma partida de futebol entre crianças, em que esta atividade se encerra com o placar de 10x0. Essa atividade será prazerosa para quem perdeu? Ou podemos pensar numa turma escolar em que o/a professor/a propõe uma atividade de pular cordas, essa atividade será prazerosa para uma criança que tenha dificuldade motora ou que esteja com grau obesidade elevado e ou por algum motivo não goste praticar essa atividade específica, mesmo assim, ser "obrigada" a praticar?

Para entender o jogo como estratégia metodológica não significa reduzi-lo a um mero instrumento didático, pois o jogo antes de tudo é uma atividade sociocultural secular e praticada por toda parte do mundo. Os jogos contribuem para promover o desenvolvimento de estruturas cognitivas, psicomotoras, afetivas e morais, criando possibilidades de construção de atitudes necessárias ao exercício da autonomia e da cidadania. O filósofo Platão, defendia que “o jogo como um meio de aprendizagem é mais prazeroso e significativo, de maneira que, inclusive, os conteúdos das disciplinas poderiam ser assimilados por meio de atividades lúdicas ${ }^{1 "}$.

Para Lima (2008, p.14), a utilização do jogo e da brincadeira como meio de ensino-aprendizagem de conteúdos das diversas áreas do conhecimento, é um importante recurso para o desenvolvimento das potencialidades inatas da criança. Ao longo do tempo, foram criados obstáculos com relação ao jogo e a brincadeira no processo educativo. Contudo, defendemos que estes podem ser utilizados de forma complementar, colaborando na superação da falsa dicotomia entre o jogar e o aprender que se instalou na escola. Para o autor,

A proposta de utilizar de forma complementar o jogo e as tarefas escolares exige do professor, por meio do processo de formação e de estudo, uma mudança de concepção, que o leve a aceitar a criança como um ser interativo, imaginativo, ativo e lúdico e descubra o potencial de desenvolvimento que está por trás das brincadeiras e dos jogos. (LIMA, 2008, p.28).

1 PLATÃO. Les lois. Cap. I e VII. Tome XI e XII, Collection des Universités de France, Paris - Les Belles Letres, 1951.

\section{plurais}

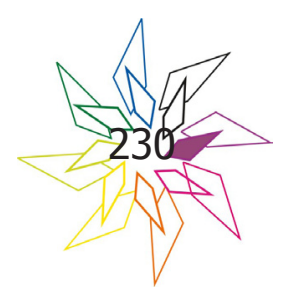




\section{Considerações Finais}

Consideramos que a partir das vivências dos jogos de origem africana e afro-brasileira no contexto escolar, proporcionam a construção dos processos educativos relacionados à valorização, conhecimento e reconhecimento da cultura africana e afro-brasileira, possibilitando aos estudantes apresentarem os seus saberes, suas descobertas, suas indagações e suas curiosidades por meio dos jogos. Assim, apresentamos o jogo como uma proposta sociocultural para o ensino, tornando-o assim, um momento de aprender-e-ensinar a respeitar, a conhecer, a reconhecer, a valorizar as diferenças culturais do nosso povo tão diverso.

Entendemos que na escola, o jogo não pode ser dissociado do processo educativo, como infelizmente tem ocorrido em muitas instituições, em especial nas aulas de Educação Física. No espaço educacional precisamos superar da falsa dicotomia entre o jogar e o aprender, para isso, existe a necessidade do/a professor/a compreender a utilização do jogo como proposta pedagógica. Dentre outras, temos algumas práticas recorrentes quando o assunto é jogo na escola. Temos observado que o jogo tem sido tratado de forma secundária, tratado como recreação, esse tipo de atividade é visto como momentos de relaxamento ou descanso das crianças, são momentos nos quais a criança pode se divertir, descontrair-se e descarregar a energia excedente. A atividade é proposta pelo/a professor/a apenas por colaborar, no descanso, na recuperação e no preparo da criança para o "ensino".

A outra perspectiva é a que adota o jogo como "proposta pedagógica" transforma as atividades lúdicas em um recurso para sedução, atração e facilitação de aprendizagens de conteúdos das diversas áreas do conhecimento em abordagens interdisciplinares. Nessa perspectiva, o jogo é utilizado como viés para ensinar. Neste artigo, defendemos que as duas atividades são de naturezas distintas, porém são conciliáveis e juntas se complementam, dentro das suas possibilidades e limitações, como recursos pedagógicos. Ressaltamos aqui a importância do/a professor/a no processo educacional, pois, ele/a, exerce o papel de mediador/a entre a criança e o processo educativo através da cultura dos jogos, e as suas intervenções é essencial para que os/as estudantes ampliem e diversifiquem os seus conhecimentos sobre jogos. Quando o/a professor/a propõe condições materiais, espaciais, temporais apropriadas e desafiadoras, possibilita que os/as educandos/as, a partir do seu repertório, brinquem, divirtam-se e aprendam com diferentes elementos da cultura.

\section{plurais}


Com certas dificuldades e limitações, entendemos que as considerações destacadas podem servir de suporte para outras práticas educativas, no que se refere à utilização do jogo como proposta sociocultural para o ensino. O jogo, portanto, é um tipo de atividade significativa, atrativa, que atende às necessidades e às possibilidades de aprendizagem e desenvolvimento das crianças. Mas, a sua secundarização é um grave equívoco cometido por muitos/as professores/as e por muitas instituições educacionais. Salientamos que devemos possibilitar formação de crianças mais críticas, solidárias, autônomas e criativas. Portanto, isso cabe ao professor/a, valorizar o brincar e o jogar, superar as dificuldades e empregar tais conteúdos como proposta pedagógica. Desta forma, concluímos que os jogos e as brincadeiras apresentam uma gama de possibilidades para prática educacional, estes, sendo utilizados com finalidades pedagógicas, podem gerar conhecimento das mais variadas áreas do conhecimento, tornando-se um importante recurso pedagógico para o ensino.

\section{REFERÊNCIAS}

ARDOINO, Jacques. Abordagem multirreferencial (plural) das situações educativas e formativas. In: BARBOSA, Joaquim Gonçalves (Org.). Multirreferencialidade nas Ciências e na Educação. p. 67-89. São Carlos: EdUFSCar, 1998.

DAOLIO, Jocimar. Educação Física e o conceito de cultura. (Coleção polémicas do nosso tempo).Campinas, SP: Autores Associados, 2004.

DIOP, Cheikh Anta. Raça, racismo e o lugar dos negros no destino da humanidade (Entrevista). In MOORE, Carlos. Racismo e sociedade. Novas bases epistemológicas para entender o racismo. Belo Horizonte: Mazza Edições, 2007.

FLEURI, Reinaldo Matias. Educação intercultural no Brasil: a perspectiva epistemológica da complexidade. R. bras. Est. pedag., Brasília, v. 80, n. 195, p. 277-289, maio/ago. 1999.

. Educação intercultural: a construção da identidade e da diferença nos movimentos sociais. p.405-423, jul./dez. Perspectiva: Florianópolis, 2002.

GIL, Antônio Carlos. Métodos e técnicas de pesquisa social. 6. ed. São Paulo: Atlas, 2008.

LARAIA, Roque de Barros. Cultura: uni conceito antropológico. 14 $4^{\mathrm{a}}$ ed. Rio de Janeiro: Jorge Zahar Ed., 2001.

LIMA, José Milton. O jogo como recurso pedagógico no contexto educacional. S. Paulo: Cultura Acadêmica: Universidade Estadual Paulista, Pró-Reitoria de Graduação, 2008.

\section{plurais}


MACEDO, Roberto Sidnei [et al]. Currículo e processos formativos: experiências, saberes e culturas. Salvador: EDUFBA, 2012.

MUNANGA, Kabengele. O conceito de africanidade nos contextos africano e brasileiro. In Jurema Oliveira (org.). Africanidades e brasilidades: culturas e territorialidades. Rio de Janeiro: Dialogarts, 2015.

NEIRA, Marcos Garcia. O Multiculturalismo Crítico e suas contribuições para o currículo da Educação Física. Temas em Educação Física Escolar. Rio de Janeiro, v. 1, n. 1, jan. /jun, p. 3-29. 2016.

PLATÃO. Les lois - Cap. I e VII. Tome XI e XII. Collection des Universités de France, Paris - Les Belles Letres, 1951.

VYGOTSKY, L. S. A formação social da mente. São Paulo: Martins Fontes, $4^{\mathrm{a}}$ ed. 1991. 1896-1934 V741L. Linguagem, Desenvolvimento e Aprendizagem. Tradução de Maria da Pena Villalobos. 11ª ed. São Paulo: Ícone, 2010.

Recebido em: 10 de março de 2020.

Inserido em: 15 de outubro de 2020.

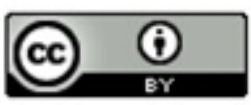

Esta obra está licenciada com uma Licença Creative Commons Atribuição 4.0 Internacional. 